\title{
Monoclonal antibody technology applied to the detection of Cryptosporidium parvum oocysts in human and cattle fecal samples
}

\author{
Vera Codices ${ }^{1}$, Olga Matos ${ }^{1}$, Carlos Novo ${ }^{2,3^{*}}$ \\ ${ }^{1}$ Unit of Medical Parasitology, Group of Opportunistic Protozoa/HIV and Other Protozoa, Centre for Malaria and Other Tropical \\ Diseases, Institute of Hygiene and Tropical Medicine, New University of Lisbon, Lisbon, Portugal \\ ${ }^{2}$ Chronic Diseases Research Centre, Oeiras Associated Laboratory, Faculty of Medical Sciences, New University of Lisbon, Lisbon, \\ Portugal \\ ${ }^{3}$ Unit of Medical Parasitology, Institute of Hygiene and Tropical Medicine, New University of Lisbon, Lisbon, Portugal \\ Email: ${ }^{*}$ cnovo@,ihmt.unl.pt
}

Received January $10^{\text {th }}, 2013$; revised March $4^{\text {th }}, 2013$; accepted April $10^{\text {th }}, 2013$

Copyright (C) 2013 Vera Codices et al. This is an open access article distributed under the Creative Commons Attribution License, which permits unrestricted use, distribution, and reproduction in any medium, provided the original work is properly cited.

\begin{abstract}
With the discovery that the coccidian parasite Cryptosporidium sp. can cause severe symptoms in humans, many diagnostic techniques were quickly implemented such as microscopic visualization, immunofluorescence and PCR. Currently, there is no effective drug treatment and none of the current diagnostic methods is $100 \%$ accurate. In this study, a BALB/C mouse was subcutaneously immunized with Cryptosporidium parvum oocysts extract. The spleen was removed and the splenocytes were fused with SP2/0 myeloma cells in order to obtain hybridoma cells secreting antibodies specific to $C$. parvum antigens. Human and cattle fecal samples previously characterized by microscopy [Ziehl-Neelsen staining (ZN) and Lugol] and PCR for the presence of $C$. parvum and Giardia duodenalis, were analyzed by indirect immunofluorescence, using the developed hybridomas supernatants. The study shows that the selected hybridomas supernatants identify C. parvum oocysts in fecal samples in correlation with $C$. parvum oocysts identified using ZN/PCR. No false positive results were obtained and the two best supernatants gave $20 \%-30 \%$ of false negative results. No cross reaction with $G$. duodenalis was observed. By comparing our results with those obtained with an immunofluorescence commercial kit, it suggests the potential use of the monoclonal antibodies present in two of the hybridomas supernatants as a detection tool of $C$. parvum. With a reliability of 80.8\% and $73.1 \%$ versus $\mathrm{ZN}$ and PCR methods for IFI, compared with a reliability of $76.9 \%$ and $92.3 \%$
\end{abstract}

"Corresponding author. versus ZN and PCR for commercial DIF kit, the supernatant 4.1D5 seems to be the most promising subject to further study its usefulness for $C$. parvum detection.

Keywords: Hybridomas; Cryptosporidium parvum; Immunofluorescence; Detection

\section{INTRODUCTION}

Cryptosporidium is an intestinal protozoan that was first recognized in mice in 1907 [1] and was first associated with diarrhea in humans in 1976 [2,3]. The disease, cryptosporidiosis, is a common gastro-intestinal illness in both animals and man worldwide, and is an important cause of morbidity and mortality in immunosuppressed individuals but self-limiting in immunocompetent hosts [4]. The infectious stages of the parasite (oocysts) are shed in the feces of infected individuals; they survive in adverse environmental conditions and are spread by direct contact or through contaminants (food and water). The high resistance of oocysts is attributed to a durable oocyst wall, a complex protective barrier consisting of a double layer of a protein-lipid-carbohydrate matrix. Due to the robustness of the oocysts, their tenacity, tiny size, and resistance to common disinfectants, it is difficult to eradicate the parasite from contaminated environments. To obtain sufficient control, both treatment of infected hosts and inactivation of oocysts are necessary [5-8].

Over the last two decades increasing numbers of cryptosporidiosis outbreaks have been recorded in developed countries, and the importance of the zoonotic species $C$. parvum is being recognized by both governmental agen- 
cies and the global scientific community [9-11]. Unlike other organisms belonging to the phylum Apicomplexa, such as Plasmodium spp. and Toxoplasma gondii, there is no clinically proven effective drug treatment against Cryptosporidium spp. [12,13].

Diagnosis is largely coprologic, although not all routine techniques have been proven to be effective. The conventional method of identification of oocysts is the examination of fecal smears stained with a modified Ziehl-Neelsen (ZN) method after oocyst concentration using a modified formol-ether sedimentation method [14]. Polymerase chain reaction (PCR) methods have been developed recently, but are used mainly in research [15-17].

Immunological detection methods have also been developed for clinical and environmental monitoring [18, 19].

Immunofluorescence techniques allow easy and quick identification of C. parvum oocysts in fecal smears after staining with monoclonal antibodies. Currently, there are several commercially available kits; however, their high price and the mandatory need of a fluorescence microscope for the smears analysis are disadvantages for the use of these techniques. There is still some controversy regarding the sensitivity of these techniques when compared with the differential staining. Some authors report that immunofluorescence is the most sensitive technique, but others describe similar sensitivities for both $[6,20]$.

Flow cytometry (FC) combines the immunofluorescence principles with the binding specificity of monoclonal antibodies, presenting a higher sensitivity than the conventional immunofluorescence techniques. Due to this fact, many authors have described their use for the detection of oocysts in fecal and environmental samples [2124]. In the context of immunologic response, FC has also been used to study the immunophenotype changes in peripheral blood and spleen cell populations due to $C$. parvum infection, in order to clarify some aspects of the cellular response to this infection [25]. Combining the principles of FC and enzyme-linked immunosorbent assay (ELISA), the Luminex $\mathrm{xMAP}^{\circledR}$ technology is also capable of performing a variety of immunoassays on the surface of fluorescence-coded beads. Recently, this highthroughput platform was used to determine the profiles of serum cytokines and immunoglobulins during an infection by C. parvum [26].

Thus, the aim of this study was to test monoclonal antibodies, produced by hybridoma technology using the spleen cells of mice immunized with oocyst extract of $C$. parvum, as a diagnostic tool in immunofluorescence assays for the detection of this parasite. With this purpose, human and cattle fecal samples infected with $C$. parvum as well as human fecal samples infected with G. duodenalis were analyzed by indirect immunofluorescence as- say (IFI) using the obtained hybridomas supernatants. The results suggest the possibility of its use for detection of C. parvum oocysts in biological samples.

\section{MATERIALS AND METHODS}

\subsection{Oocyst Extract Preparation}

Purified oocysts of $C$. parvum (Morendun) obtained from cattle were purchased from Creative Science Company/ Morendun Institute (Edinburgh, Scotland). According to the supplier, oocysts were resuspended in phosphate buffered saline (PBS) and stored at $4^{\circ} \mathrm{C}$ in the presence of antibiotics (penicillin and streptomycin). The viability of the oocysts preparation, checked by in vitro excystation, was $94.7 \%$.

C. parvum crude soluble extract was prepared by sonication of oocysts with few modifications to the method described in [27]. Briefly, a total of $1 \times 10^{6}$ C. parvum oocysts were solubilized $\left(30 \mathrm{~min}\right.$ at $\left.4^{\circ} \mathrm{C}\right)$ in lysis buffer [50 mM Tris (AppliChem), $5 \mathrm{mM}$ EDTA (Merck), $5 \mathrm{mM}$ iodoacetamide (Sigma), $0.1 \mathrm{mM} \mathrm{N} \alpha$-tosyl-L-lysine chloromethyl ketone hydrochloride (Sigma), $1 \mathrm{mM}$ phenylmethylsulfonyl fluoride (Sigma), 1\% (w/v) octyl beta-Dglucopyranoside (Sigma)] and stored at $-80^{\circ} \mathrm{C}$. Upon thawing, samples were sonicated (Sonoplus HD2070, Bandelin, Germany) with 20 pulses of 1 -min $(80 \%, 2$ cycles; $60 \%, 4$ cycles) on ice at 1-min intervals followed by an ultracentrifugation at $4^{\circ} \mathrm{C}(20,000 \mathrm{~g}$ for $30 \mathrm{~min})$ to separate the soluble and insoluble fractions. The soluble fraction was used as crude soluble antigen of Cryptosporidium and protein concentration determined by Bradford's method using $2 \mathrm{mg} / \mathrm{ml}$ bovine serum albumin (BSA) as standard. Absorbance readings were performed at 595 $\mathrm{nm}[28]$.

\subsection{Immunization}

One four-week-old female BALB/C ByJ mouse was obtained from Charles River Laboratories (France). The mouse was housed in a sterilized plastic cage with filter top, and fed with sterilized food and water $(\mathrm{pH} 3.5)$ ad libitum under SPF conditions. Seven subcutaneous immunizations of $10 \mu \mathrm{g}$ of soluble antigen emulsified in incomplete Freund's adjuvant (Sigma) $(1: 1 \mathrm{v} / \mathrm{v})$ were administered with intervals of fifteen days. The experiments involving animals were performed in accordance with the national and international laws and institutional guidelines.

\subsection{Serum Titer Determination}

Fifteen days after the last immunization, a blood sample was collected by end tail cut. Serum obtained by centrifugation of the collected blood sample at $1500 \mathrm{rpm}$ for 5 min at $4^{\circ} \mathrm{C}$ was stored at $-20^{\circ} \mathrm{C}$ until use. Serum anti- 
body titer was determined by indirect ELISA, adapted from $[29,30]$. Briefly, 96-well microtiter plates (NuncImmuno ${ }^{\mathrm{TM}}$ Plate Polysorp, USA) were coated overnight at $4^{\circ} \mathrm{C}$ with $0.1 \mathrm{mg} / \mathrm{ml}$ poly-L-lysine in $0.5 \mathrm{M}$ carbonate buffer, $\mathrm{pH} 9.5$, by adding $100 \mu \mathrm{l}$ into each well. After washing once with PBS, $1 \mu \mathrm{g}$ of antigen dissolved in carbonate buffer containing $0.5 \%$ glutaraldehyde, was added to each well and incubated for $2 \mathrm{hr}$ at $37^{\circ} \mathrm{C}$; followed by the addition of $100 \mathrm{mM}$ glycine $0.1 \%$ BSA and incubation for $20 \mathrm{~min}$ at room temperature. Plates were blocked with $2 \%$ gelatin in PBS for $1 \mathrm{~h}$ at room temperature. After another wash with PBS-T $(0.05 \%$ Tween 20-PBS), five serial serum dilutions (1:100, 1:200, 1:400, 1:800 and 1:1600 in PBS) were added one to each well, and the plate incubated for $1 \mathrm{~h}$ at $37^{\circ} \mathrm{C}$. After four washes with PBS-T, the Anti-Mouse Immunoglobulins (G, A, M) Alkaline Phosphatase conjugated serum (Sigma) (diluted 1:5000 in PBS/T-0.1\% BSA) was added and incubated for an extra hour at $37^{\circ} \mathrm{C}$. After washing the plates five times with PBS-T, $100 \mu \mathrm{l}$ of the substrate solution containing $1 \mathrm{mg} / \mathrm{ml} p$-nitrophenyl phosphate (Sigma) in 10 $\mathrm{mM}$ ethanolamine buffer, $\mathrm{pH}$ 9.6, was added. After 30 min of incubation in the dark at room temperature, the absorbance was measured at $405 \mathrm{~nm}$ in an ELISA microplate reader (NanoQuant Infinite M200 Pro, Tecan, Männedorf, $\mathrm{CH}$ ). The negative control of the reaction was performed using the serum collected from the same mouse, prior to inoculation with the antigen extract. A blank was run in parallel on the same plate and all the samples were run in duplicate.

\subsection{Cell Culture and Hybridoma Generation}

$10^{8}$ splenocytes collected from the immunized mouse spleen were fused with $10^{7} \mathrm{SP} 2 / 0$ myeloma cells previously grown in Dulbecco's Modified Eagle's Medium (DMEM) (Invitrogen) supplemented with 20\% fetal calf serum (FCS) (Sigma), $0.2 \mathrm{mg} / \mathrm{ml}$ gentamicin (Sigma), using 40\% PEG 1500 (Roche) as fusogenic agent, adapted from the protocol described in [31]. The resulting cell fusion products were distributed over $8 \times 96$-well flatbottom plates and hybridoma cells selected in DMEM supplemented with $20 \%$ FCS, gentamicin $(0.2 \mathrm{mg} / \mathrm{ml})$, containing hypoxanthine $\left(1 \times 10^{-4} \mathrm{M}\right)$-aminopterin $(4 \times$ $10^{-5} \mathrm{M}$ )-thymidine $\left(1.6 \times 10^{-5} \mathrm{M}\right)$ (HAT medium) (Sig$\mathrm{ma}$ ) and incubated at $37^{\circ} \mathrm{C}, 5 \% \mathrm{CO}_{2}, 95 \%$ humidity. Hybridoma culture supernatants were screened for the presence of antibodies towards C. parvum antigens by ELISA in the manner described previously for serum titer determination. Hybridomas supernatants whose ELISA absorbance value was at least, three times higher than the absorbance value of the blank were expanded in HAT medium at $37^{\circ} \mathrm{C}, 5 \% \mathrm{CO}_{2}, 95 \%$ humidity. After growing, hybridomas cells were frozen in liquid nitrogen at $-80^{\circ} \mathrm{C}$ and the cell culture supernatants were used for indirect immunofluorescence assay.

\subsection{Indirect Immunofluorescence Assay}

The ELISA selected hybridomas supernatants were tested in duplicate by indirect immunofluorescence (IFI) assay for binding to C. parvum pure oocysts (Morendun), adapted from $[32,33]$. To the pre-treated slides with polyL-lysine (Polysine ${ }^{\circledR}$ slides, Thermo Scientific) $25 \mu \mathrm{l}$ of $C$. parvum pure oocysts were applied to the surface, airdried at room temperature, and fixed with methanol. Slides were incubated with $30 \mu l$ per application of the selected hybridomas supernatants for $30 \mathrm{~min}$ at $37^{\circ} \mathrm{C}$, in a $100 \%$ humidified chamber at $37^{\circ} \mathrm{C}$, followed by one wash with PBS. After being air-dried at room temperature, slides were incubated with fluorescein-isothiocyanate (FITC)-conjugated goat anti-mouse immunoglobulin (Sigma) diluted at 1:400 (25 $\mu \mathrm{l}$ per application) for 30 min in the same humidity and temperature conditions. Subsequently, after a thorough wash with PBS and airdrying at room temperature, preparations were covered with two drops of mounting medium, and examined under an Olympus Fluorescence microscope equipped with an ultraviolet lamp, at $490-520 \mathrm{~nm}$ and $596-620 \mathrm{~nm}$, with a magnification of $400 \times$. As positive control of the assay, we used the commercial kit (Crypt-a-Glo ${ }^{\mathrm{TM}}$, A400FLR-1X, Waterborne, Inc., New Orleans, Los Angeles) for direct immunofluorescence (DIF) of C. parvum pure oocysts, at the same magnification.

\subsection{Fecal Samples Analysis by Immunofluorescence Using the Hybridomas Supernatants}

The hybridomas supernatants that showed a better capability to detect $C$. parvum pure oocysts by the IFI protocol described above, were tested for the capability to detect $C$. parvum in human and cattle fecal samples, 10 samples known to be positive for $C$. parvum by both $\mathrm{ZN}$ and nested-PCR $\left(\mathrm{ZN}^{+} / \mathrm{PCR}^{+}\right)$; eight samples known to be negative by $\mathrm{ZN}$ and positive by nested-PCR $\left(\mathrm{ZN}^{-} / \mathrm{PCR}^{+}\right)$; and eight samples considered negative by both $\mathrm{ZN}$ and nested-PCR $\left(\mathrm{ZN}^{-} / \mathrm{PCR}^{-}\right)$.

In addition, the same hybridomas supernatants listed above were also tested for possible cross-reactivity with G. duodenalis, using the same IFI protocol, applied to 10 human fecal samples, all negative for $C$. parvum by $\mathrm{ZN}$ and nested-PCR ( $\left.\mathrm{ZN}^{-} / \mathrm{PCR}^{-}\right)$and positive for $G$. duodenalis by microscopy (Lugol staining) and nested-PCR. Cryptosporidium oocysts in human and cattle fecal samples and $G$. duodenalis cysts in human fecal samples were detected on fecal smears after concentration using a modified formol-ether sedimentation method followed by a modified ZN staining [14] and Lugol staining, re- 
spectively; and observed under an optical microscope with $400 \times$ magnification. After extraction of DNA by a Mini-BeadBeater/silica method [34], the presence of $C$. parvum DNA in fecal samples was confirmed by a nested-PCR of the $60-\mathrm{kDa}$ glycoprotein (GP60) gene [16, 17]. A nested-PCR was used to amplify the $\beta$-giardin gene of G. duodenalis [35].

The control of the commercial kit Crypt-a-Glo, which contains both parasites (C. parvum and G. duodenalis), was used as positive control.

\section{RESULTS}

\subsection{Hybridomas Screening}

The ELISA screening of the cell supernatants obtained from wells with hybridomas cells showed that circa 200 wells presented hybridomas producing antibodies against C. parvum antigens, representing $26 \%$ of the total distributed cell fusion products wells. From those, only 16 hybridomas supernatants showed an absorbance value, at least, three times higher than the absorbance value of the blank (Absorbance $=0.132$ ), ranging from 0.361 to 2.069 .

\subsection{Indirect Immunofluorescence Assay}

To select which of the 16 ELISA positive hybridoma supernatants could detect the parasite by fluorescence emission, these supernatants were tested by IFI against $C$. parvum pure oocysts (Morendun) and the recognition pattern compared with that of DIF detection of C. parvum pure oocysts with the Crypt-a-Glo kit. From those, four hybridomas supernatants (4.1D5, 7.1D5, 3.1C5 and 6.2C6) gave a pattern consistent with this assumption (Figure 1). The remaining 12 hybridoma cell culture

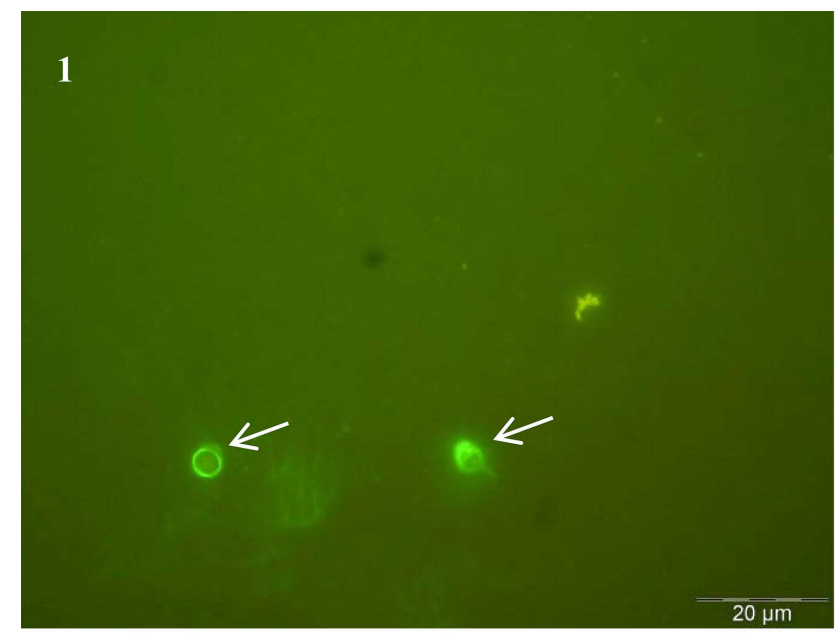

supernatants present oocysts with a much weaker fluorescence than the observed for the oocysts from the kit positive control and, therefore, they were not selected for further assays.

In the next step, the four selected hybridomas supernatants (4.1D5, 7.1D5, 3.1C5 and 6.2C6) were checked in a known sample containing $C$. parvum oocysts and $G$. duodenalis cysts (kit positive control), for their binding capacity to both parasites (cross reaction), and differences in the extension of recognition (quantification) as well as their fluorescence pattern (different epitopes distribution). The results showed that the hybridomas supernatants 4.1D5 and 7.1D5 detected with great specificity a large amount of $C$. parvum oocysts. The hybridomas supernatants $3.1 \mathrm{C} 5$ and $6.2 \mathrm{C} 6$ also detected $C$. parvum oocysts, but in much less extension than the two first hybridomas supernatants. None of the four hybridomas supernatants detected Giardia cysts, only a few "ghosts" were observed due to the background fluorescence.

\subsection{Fecal Samples Analysis by Immunofluorescence Using the Hybridomas Supernatants}

The four selected hybridomas supernatants were tested in human and cattle fecal samples, by IFI, and the results are described in Table 1. In the 10 fecal samples $\mathrm{ZN}^{+} /$ $\mathrm{PCR}^{+}$, the highest percentage of positive results was obtained with hybridomas supernatants 4.1D5 and 7.1C5, which gave positive results in $80 \%$ and $70 \%$ of the samples, respectively. Hybridomas supernatants 3.1C5 and 6.2C6 only detected C. parvum oocysts in $40 \%$ of fecal samples $\mathrm{ZN}^{+} / \mathrm{PCR}^{+}$. In the eight fecal samples $\mathrm{ZN}^{-} / \mathrm{PCR}^{+}$, all hybridomas supernatants detected $C$. parvum oocysts, which occurred in $25 \%$ to $37.5 \%$ of the tested

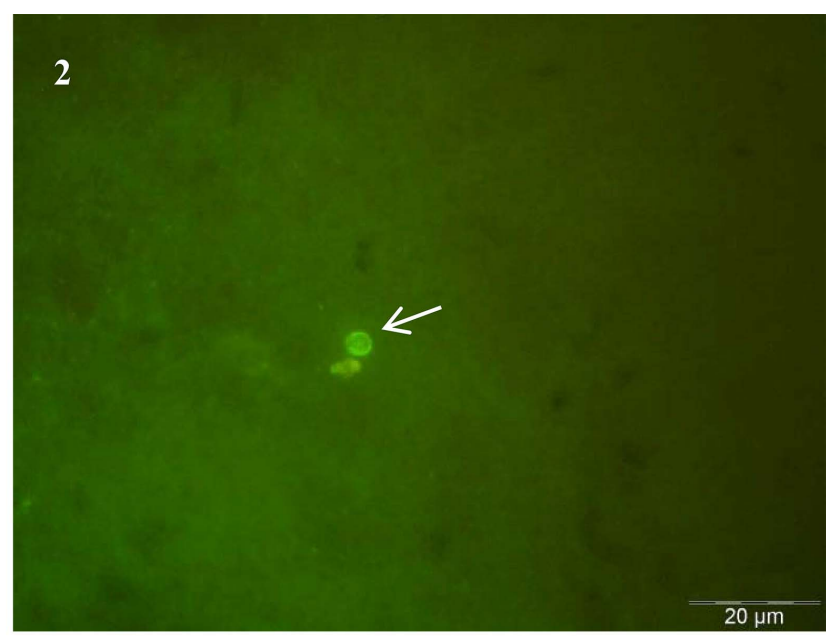

Figure 1. C. parvum oocysts detected by immunofluorescence assay $(1000 \times)$. The image 1 represents the positive control and shows the $C$. parvum pure oocysts stained with FITC-labeled monoclonal antibody reagent from the kit Crypt-a-Glo ${ }^{\mathrm{TM}}$ (DIF). The image 2 shows the detection of C. parvum pure oocysts with one of the four selected hybridoma supernatants, by IFI. Oocysts are indicated with white arrows. 
Table 1. Indirect immunofluorescence assay (IFI) for hybridomas supernatants specificity against human and cattle fecal samples. The first column represents the number of analyzed fecal samples, with the respective result for ZN staining and PCR. From the second to the fifth column are shown the results of testing the hybridomas supernatants (4.1D5, 7.1D5, 3.1C5 and 6.2C6) with each group of fecal samples.

\begin{tabular}{|c|c|c|c|c|c|c|c|c|}
\hline \multirow{3}{*}{ Human and cattle fecal samples } & \multicolumn{8}{|c|}{ Hybridomas supernatants } \\
\hline & \multicolumn{2}{|c|}{$4.1 \mathrm{D} 5$} & \multicolumn{2}{|c|}{ 7.1D5 } & \multicolumn{2}{|c|}{$3.1 \mathrm{C} 5$} & \multicolumn{2}{|c|}{$6.2 \mathrm{C} 6$} \\
\hline & $\mathbf{P}$ & $\mathbf{N}$ & $\mathbf{P}$ & $\mathbf{N}$ & $\mathbf{P}$ & $\mathbf{N}$ & $\mathbf{P}$ & $\mathbf{N}$ \\
\hline $\begin{array}{c}\mathbf{Z N}^{+} / \mathbf{P C R}^{+} \\
\mathrm{n}=10\end{array}$ & $\begin{array}{c}8 \\
(80 \%)\end{array}$ & $\begin{array}{c}2 \\
(20 \%)\end{array}$ & $\begin{array}{c}7 \\
(70 \%)\end{array}$ & $\begin{array}{c}3 \\
(30 \%)\end{array}$ & $\begin{array}{c}4 \\
(40 \%)\end{array}$ & $\begin{array}{c}6 \\
(60 \%)\end{array}$ & $\begin{array}{c}4 \\
(40 \%)\end{array}$ & $\begin{array}{c}6 \\
(60 \%)\end{array}$ \\
\hline $\begin{array}{c}\mathbf{Z N}^{-} / \mathbf{P C R}^{+} \\
\mathrm{n}=8\end{array}$ & $\begin{array}{c}3 \\
(37.5 \%)\end{array}$ & $\begin{array}{c}5 \\
(62.5 \%)\end{array}$ & $\begin{array}{c}3 \\
(37.5 \%)\end{array}$ & $\begin{array}{c}5 \\
(62.5 \%)\end{array}$ & $\begin{array}{c}2 \\
(25 \%)\end{array}$ & $\begin{array}{c}6 \\
(75 \%)\end{array}$ & $\begin{array}{c}3 \\
(37.5 \%)\end{array}$ & $\begin{array}{c}5 \\
(62.5 \%)\end{array}$ \\
\hline $\begin{array}{c}\mathbf{Z N}^{-} / \mathbf{P C R}^{-} \\
\mathrm{n}=8\end{array}$ & $\begin{array}{c}0 \\
(0 \%)\end{array}$ & $\begin{array}{c}8 \\
(100 \%)\end{array}$ & $\begin{array}{c}0 \\
(0 \%)\end{array}$ & $\begin{array}{c}8 \\
(100 \%)\end{array}$ & $\begin{array}{c}0 \\
(0 \%)\end{array}$ & $\begin{array}{c}8 \\
(100 \%)\end{array}$ & $\begin{array}{c}0 \\
(0 \%)\end{array}$ & $\begin{array}{c}8 \\
(100 \%)\end{array}$ \\
\hline
\end{tabular}

$\mathrm{P}=$ positive by IFI $\mathrm{N}=$ negative by IFI.

samples. When the hybridomas supernatants were tested in the eight fecal samples that were negative by $\mathrm{ZN}$ and PCR, neither $C$. parvum oocysts nor $G$. duodenalis cysts were detected in any tested samples by any of the tested hybridomas supernatants.

When applied to the 10 human fecal samples positive for G. duodenalis using the same IFI protocol, none of the four selected hybridomas supernatants detected Giardia cysts in any of the samples.

In order to validate our immunofluorescence results, the previously used 26 human and cattle fecal samples were tested by DIF with the commercial kit Cryp-a-Glo and the results compared with those obtained with the two selected hybridomas supernatants (4.1D5 and 7.1D5), as they were the two supernatants presenting the best correlation with the ZN/PCR results (Figure 2). In the $\mathrm{ZN}^{+} / \mathrm{PCR}^{+}$samples, the whole group was positive for $C$. parvum oocysts $(100 \%)$, while with the two best supernatants we obtained positive results between $70 \%-80 \%$. For the group of samples $\mathrm{ZN}^{-} / \mathrm{PCR}^{+}$, the commercial kit detected C. parvum oocysts in $75 \%$ of samples, while the two selected supernatants gave positive results in $37.5 \%$ of the samples. In the group of samples $\mathrm{ZN}^{-} / \mathrm{PCR}^{-}$, all the samples analyzed were negative, in both the commercial kit and the two hybridomas supernatants, indicating a $100 \%$ agreement. A similar agreement $(100 \%$ negativity) was observed for the results obtained for the human fecal samples, positive for G. duodenalis and negative for C. parvum.

Reliability is the extent to which an experiment or test procedure yields the same or compatible results on repeated assays. In this context, reliability was defined as the percentage of agreement between the analysis of fecal samples by IFI (with the hybridomas supernatants) and the reference method (ZN or PCR); and the percentage of agreement between the analysis of fecal samples by DIF (with the commercial kit) and the reference method (ZN or PCR). The reliability results obtained are described in Table 2. From the total of 26 fecal samples analyzed, the highest reliability value between IFI and the reference method $(\mathrm{ZN})$ was observed for the supernatant 4.1D5 (80.8\%), better than for the commercial kit $(76.9 \%)$. The analysis of the 26 fecal samples by DIF (with the commercial kit) and the reference methods ( $\mathrm{ZN}$ and PCR) showed that the reliability with PCR (92.3\%) was higher than reliability with ZN (76.9\%). However, it is noted that although the reliability with our 4.1D5 supernatant $(80.8 \%)$ is lower than PCR $(92.3 \%)$, it is higher than $\mathrm{ZN}(76.9 \%)$.

\section{DISCUSSION}

There is an increasing demand for diagnostic testing for C. parvum, with a priority being placed on obtaining diagnostic results in an efficient and timely manner. Staining of fecal smears may help to identify Cryptosporidium oocysts and despite being an inexpensive technique, it still requires experienced personnel for the microscopic examination of stained smears capable of differentiating oocysts from similarly stained particles such as spores of fungi or yeast and oocysts, which is time consuming $[14,36]$. Direct and indirect immunofluorescence assays are more costly than the conventional microscopic techniques, but oocysts are readily identified, based on the three recommended criteria which are 1) characteristic apple-green fluorescence delineating the oocyst wall, under the FITC filter; 2) round or slightly ovoid objects; 3) and a size of 4 to $6 \mu \mathrm{m}$ in diameter [37-39]. On the other hand, the PCR is still a more expensive technique than the immunofluorescence, more time consuming, and require specialized personnel and expensive equipment [6].

From the 16 hybridomas supernatants ELISA positive, four bonded to C. parvum pure oocysts and gave a fluorescence pattern which was consistent with that observed for DIF of the same samples using the commercial kit Cryp-a-Glo. The number of oocysts detected in each as- 


\begin{tabular}{|c|c|c|c|c|c|c|}
\hline \multicolumn{4}{|c|}{ Hybridomas supernatants } & \multirow{3}{*}{$\begin{array}{c}\text { Human and } \\
\text { cattle fecal } \\
\text { samples }\end{array}$} & \multicolumn{2}{|c|}{ Crypt-a-Glo kit } \\
\hline \multicolumn{2}{|c|}{ 4.1D5 } & \multicolumn{2}{|c|}{7.105} & & & \\
\hline P1 & N1 & P1 & N1 & & $\mathrm{P} 2$ & $\mathbf{N} 2$ \\
\hline 8 & 2 & 7 & 3 & $\mathbf{Z N}^{+} / \mathbf{P C R}^{+}$ & 10 & 0 \\
\hline$(80 \%)$ & $(20 \%)$ & $(70 \%)$ & $(30 \%)$ & $\mathrm{n}=10$ & $(100 \%)$ & $(0 \%)$ \\
\hline $\begin{array}{c}3 \\
(37.5 \%)\end{array}$ & $\begin{array}{c}5 \\
(62.5 \%)\end{array}$ & $\begin{array}{c}3 \\
(37.5 \%)\end{array}$ & $\begin{array}{l}5 \\
(62.5 \%)\end{array}$ & $\begin{array}{c}\mathbf{Z N}^{-} / \mathbf{P C R}^{+} \\
\mathrm{n}=8\end{array}$ & $\begin{array}{c}6 \\
(75 \%)\end{array}$ & $\begin{array}{c}2 \\
(25 \%)\end{array}$ \\
\hline $\begin{array}{c}0 \\
(0 \%)\end{array}$ & $\begin{array}{c}8 \\
(100 \%)\end{array}$ & $\begin{array}{c}0 \\
(0 \%)\end{array}$ & $\begin{array}{c}8 \\
(100 \%)\end{array}$ & $\begin{array}{c}\mathbf{Z N}^{-} / \mathbf{P C R}^{-} \\
\mathrm{n}=8\end{array}$ & $\begin{array}{c}0 \\
(0 \%)\end{array}$ & $\begin{array}{c}8 \\
(100 \%)\end{array}$ \\
\hline
\end{tabular}
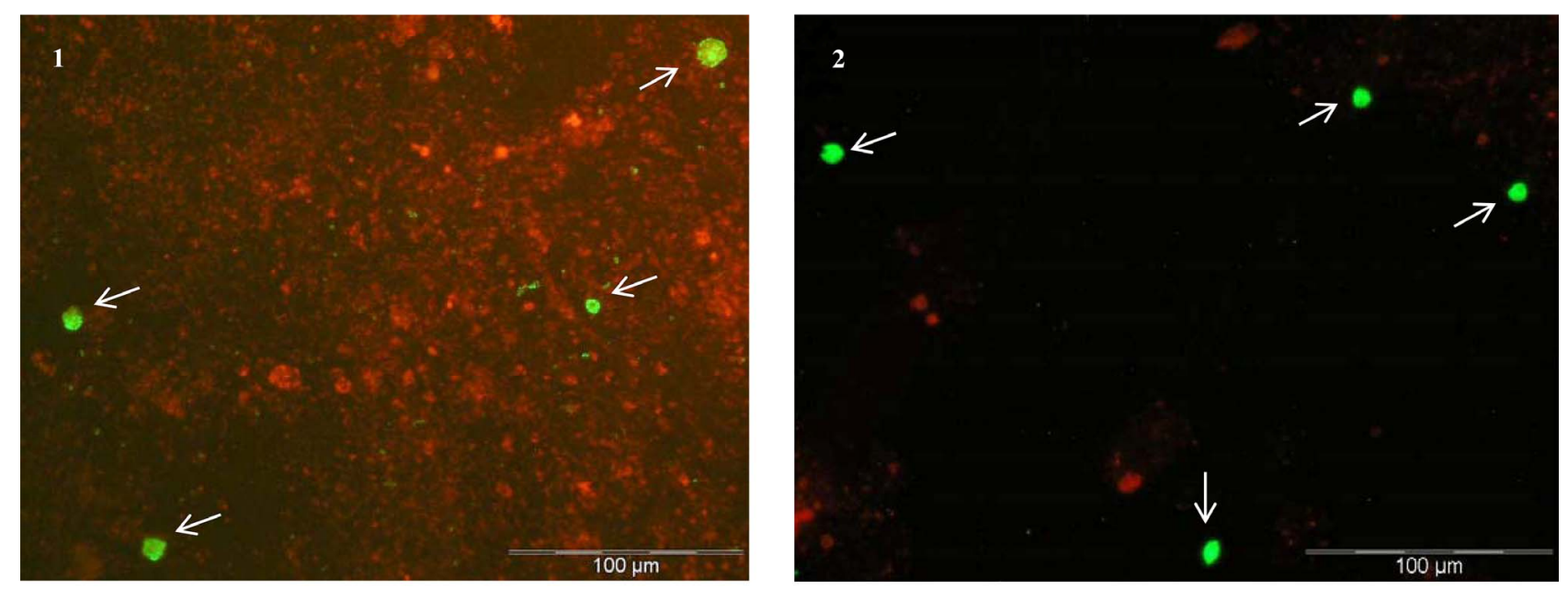

Figure 2. Direct and indirect immunofluorescence assay of human and cattle fecal samples with hybridomas supernatants and the commercial kit Crypt-a-Glo. In the table, the two first columns represent the results of testing, by IFI, the two best hybridomas supernatants (4.1D5 and 7.1D5) with each group of fecal samples. The third column represents the number of analyzed fecal samples with the respective result for ZN staining and PCR. The fourth column shows the result of testing the fecal samples by DIF with the kit. The images 1 and 2 show one of the samples tested by IFI with one of the referred hybridoma and tested by DIF with the commercial kit, respectively $(400 \times)$. Oocysts are indicated with white arrows. P1 = positive by IFI; N1 = negative by IFI; P2 = positive by DIF; N2 = negative by DIF.

Table 2. Reliability percentages values between direct and indirect immunofluorescence assays with the reference methods, ZN and PCR. The data in the equations concerning the IFI and DIF results were transcribed from table 1 and table in Figure 2, respectively. The percentage of agreement between the analysis of the 26 fecal samples by IFI (with the hybridomas supernatants 4.1D5, 7.1D5, $3.1 \mathrm{C} 5$ and 6.2C6) and the reference method is presented from the second to the fifth column of the table. The sixth column represents the percentage of agreement between the analysis of the 26 fecal samples by DIF (with the commercial kit Crypt-a-Glo) and the reference method.

\begin{tabular}{cccccc}
\hline \multirow{2}{*}{ Reference method } & \multicolumn{2}{c}{ IFI (hybridomas supernatants) } & DIF \\
\cline { 2 - 5 } & $4.1 \mathrm{D} 5$ & $7.1 \mathrm{D} 5$ & $3.1 \mathrm{C} 5$ & $6.2 \mathrm{C6}$ & (commercial kit) \\
\hline \multirow{2}{*}{ ZN } & $80.8 \%$ & $76.9 \%$ & $69.2 \%$ & $65.4 \%$ & $76.9 \%$ \\
& {$[(8+5+8) / 26]$} & {$[(7+5+8) / 26]$} & {$[(4+6+8) / 26]$} & {$[(4+5+8) / 26]$} & {$[(10+2+8) / 26]$} \\
\multirow{2}{*}{ PCR } & $73.1 \%$ & $69.2 \%$ & $53.8 \%$ & $57.7 \%$ & $92.3 \%$ \\
& {$[(8+3+8) / 26]$} & {$[(7+3+8) / 26]$} & {$[(4+2+8) / 26]$} & {$[(4+3+8) / 26]$} & {$[(10+6+8) / 26]$} \\
\hline
\end{tabular}

say by two of the hybridomas supernatants (4.1D5 and 7.1D5) was identical to the oocysts identified in the sample by the kit. This led us to consider the hypothesis that these two hybridomas supernatants may be more specific for the detection of $C$. parvum than the others.

Cross-reactions can occur in immunofluorescence tests, as the presence of a large number of fluorescent particles may cause difficulties during the microscopic confirmation of suspected oocysts [40,41]. In the present work, the specificity of the anti-Cryptosporidium hybridomas supernatants was tested regarding cross-reaction with $G$. duodenalis cysts using a known sample (kit positive con- 
trol) as well as characterized human fecal samples by microscopy and PCR, positive for the presence of Giardia cysts and negative for the presence of Cryptosporidium oocysts. No Giardia cysts were detected in any of the tested samples, suggesting that there is no cross reaction with $G$. duodenalis. Despite the large morphological difference between oocysts and cysts, the intent of the specificity test was to precisely observe the presence of possible components in the cysts that might be recognized by the anti-Cryptosporidium hybridomas supernatants.

The results on fecal samples obtained by using the three methods (ZN, PCR and IF) for the diagnosis of Cryptosporidium infection did not give the same results. The two best hybridomas supernatants 4.1D5 and 7.1D5 detected C. parvum oocysts, by IFI, in $70 \%-80 \%$ of the $\mathrm{ZN}^{+} / \mathrm{PCR}^{+}$samples. Since the results of nested-PCR only shows the presence of C. parvum DNA, the positive result observed with $\mathrm{ZN}$ staining is exclusively due to the presence of $C$. parvum oocysts. The $20 \%-30 \%$ false negatives obtained by immunofluorescence analysis using the hybridomas supernatants 4.1D5 and 7.1D5 may probably be explained by the differences in the targets of ZN staining and antibody binding. In those cases, where the oocysts presented a certain level of degradation but still maintaining the overall morphological structure, enough for $\mathrm{ZN}$ detection, this degradation may be sufficient to change the conformation and/or access of the protein present in the oocyst membrane, and targeted by the supernatant antibodies with the consequent negative result by IFI.

For $\mathrm{ZN}^{-} / \mathrm{PCR}^{-}$samples, a $100 \%$ agreement was obtained between immunofluorescence analysis by those hybridomas supernatants and the comparative methods, $\mathrm{ZN}$ and PCR, which suggests that the samples were true negatives.

In the group of $\mathrm{ZN}^{-} / \mathrm{PCR}^{+}$samples, these two hybriddomas supernatants detected C. parvum oocysts in 37.5\% of the samples. The PCR positive result indicated the presence of C. parvum DNA in all samples. Because of the $\mathrm{ZN}$ negative results, it suggests that there were no morphological intact oocysts or they were present in a very small amount or even they were non-homogeneously distributed in the stool samples. This discrepancy might be in accordance with the oocysts degradation, also suggesting an increased sensitivity of IFI over the $\mathrm{ZN}$ staining to detect oocysts. In fact, the ZN method has a low sensitivity when dealing with samples with low parasite burden, and excessive staining can result in false positive reactions from yeast cells, particularly when the oocysts are present in small numbers. The oocysts are acid-fast but their staining within a smear and between specimens are very variable, and oocysts vary from unstained to partial red and complete staining [14]. With regard to the other two hybridomas supernatants (3.1C5 and 6.2C6), the results suggest that they have low affinity towards the recognized C. parvum protein(s).

The reliability of the two best supernatants 4.1D5 $(80.8 \%)$ and $7.1 \mathrm{D} 5(76.9 \%)$ relative to $\mathrm{ZN}$ staining, combined with the $20 \%-30 \%$ of false negative detection, suggest that these supernatants might contain promising antibodies to be included in an immunofluorescence diagnosis kit for $C$. parvum in biological samples from different sources. The higher reliability value between IFI vs ZN (80.8\%) than IFI vs PCR (73.1\%), and the higher variability between the commercial kit vs PCR $(92.3 \%)$ than the commercial kit vs ZN $(76.9 \%)$, suggest that the supernatant 4.1D5 is more reliable than the commercial kit relative to $\mathrm{ZN}$ staining. Although, this supernatant (4.1D5) is less reliable relative to the commercial kit when compared with PCR. From the reliability results it is possible to notice that, the supernatant 4.1D5 seems to be the most promising for further studies for its usefulness for C. parvum infection diagnosis, once it detects a higher number of positive $\mathrm{ZN}$ samples than the monoclonal antibody of the commercial kit.

There are few marketed kits for reliable detection of $C$. parvum oocysts by immunofluorescence assay. Other than the kit used in this work, another kit has been used as reference method in several comparative studies with stained methods and enzyme immunoassays, the Merifluor $^{\mathrm{TM}}$ Cryptosporidium kit $[42,43]$. The ease of interpretation of results varied considerably for each assay. The acid-fast stained smears were more difficult to interpret, requiring frequent examination with oil magnification to identify the organisms. The Merifluor test was extremely easy to read as the brilliant apple-green-fluorescent organisms with typical morphology were visible at $400 \times$ and could be easily identified, thus requiring much less reading time and technician expertise. The test required a fluorescent microscope, which despite being expensive, is becoming a standard piece of equipment in many laboratories. These diagnostic kits do not take the place of routine stained smears but they have proven to be very useful when trying to confirm Cryptosporidium infections, and can be used for confirmation testing when the technician is unfamiliar with the organism. Thus, the results obtained with both kits, Merifluor and Crypt-aGlo, corroborate with those obtained in this study.

When comparing the immunofluorescence assay with the $\mathrm{ZN}$, we conclude that the first is a highly sensitive and specific technique which requires less reading time than the staining method when the oocysts are present in low numbers. Although the reagent cost is higher, requiring the availability of a fluorescence microscope (present in the majority of laboratories nowadays), the reduction in cost from the decreased need for technician expertise and reading time must also be considered. Mo- 
lecular methods (PCR) are more widely used for genotyping and molecular epidemiological studies, and may have greater sensitivity than the immunofluorescence techniques, once the target is different (DNA for PCR and oocyst for IF). However, the processing of the samples requires the use for a large number of equipment, which translates into higher cost, more difficult to support by the laboratories, especially in developing countries (e.g. Africa and Latin America) and specialized personnel. Also, the import of immunofluorescence kits is costly for laboratories to monitor the parasites. Due to the aforementioned factors, it is important to conduct studies, such as the present work, for the purpose of developing reliable, specific, and less costly testing methods.

Here, we tested monoclonal antibodies produced by hybridoma technology using the spleen cells of mice immunized with oocyst extract of C. parvum, as a diagnostic tool in immunofluorescence assays for the detection of this parasite. We believe that this first initiative to produce antibodies in-house for immediate use is the starting point for immunodetection of Cryptosporidium and the results seem to indicate that it can be used for screening of samples from different origins. In this context, this might be a possible way to produce antibodies, in a less expensive way, to be used in developing countries.

However, the sensitivity of the immunofluorescence method by itself is still low, with the detection limit nearly to 10,000 oocysts per gram of watery stool and lower in the case of more formed stools [22,24]. FC may be considered as an alternative to the conventional immunofluorescence method, and few studies have already addressed the cytometric detection of Cryptosporidium in feces and water $[22,24,44,45]$. Even though cytometry currently requires expensive equipment, such equipment is present in many immunology laboratories (sometimes underutilized) and could often be shared by parasitologists. FC can be applied to small sample volumes and to the analysis of a very high number of samples in a reduced time, decreasing the cost of each analysis, reagents, and consumables. Combining the advantages of FC with the benefits of producing antibodies in-house, it would be expected to achieve optimal costs at several levels, making this combination an attractive option to be used in more laboratories.

The production of monoclonal antibodies produced by hybridoma(s) present in selected hybridoma(s) supernatants will be the next step to be developed by this research group. A full characterization of these antibodies will be done identifying their affinity, sensitivity, specificity correlation, reproducibility and the extended crossreaction study to other microorganisms such as Eimeria sp, Campylobacter jejuni, Escherichia coli, Salmonella typhimurium, Salmonella enteritidis. The analysis of those parameters in a high number of samples containing different $C$. parvum isolates from different sources will be expected to characterize these antibodies in order to validate its use in conventional indirect immunofluorescence commercial kits, as well in analysis by flow cytometry. Further studies are needed to develop methods to reduce the percentage of false negative results in the detection of C. parvum by the hybridoma(s) supernatant(s), before it evolves as an effective screening tool for the detection of this microorganism.

\section{ACKNOWLEDGEMENTS}

We would like to express our gratitude to Moussa Elbayoumy, MD, for critical review and linguistic editing.

Vera Codices was supported by a Ph.D. grant (SFRH/BD/46558/ 2008) from Fundação para a Ciência e a Tecnologia (Portugal).

\section{REFERENCES}

[1] Tyzzer, E.E. (1907) A sporozoan found in the peptic glands of the common mouse. Proceedings of the Society for Experimental Biology and Medicine. Society for Experimental Biology and Medicine, 5, 12-13. http://ebm.rsmjournals.com/content/5/1/12.extract

[2] Meisel, J.L., Perera, D.R., Meligro, C. and Rubin, C.E. (1976) Overwhelming watery diarrhea associated with a cryptosporidium in an immunosuppressed patient. Gastroenterology, 70, 1156-1160.

[3] Nime, F.A., Burek, J.D., Page, D.L., Holscher, M.A. and Yardley, J.H. (1976) Acute enterocolitis in a human being infected with the protozoan Cryptosporidium. Gastroenterology, 70, 592-598.

[4] O'Donoghue, P.J. (1995) Cryptosporidium and cryptosporidiosis in man and animals. International Journal for Parasitology, 25, 139-195. doi:10.1016/0020-7519(94)E0059-V

[5] Mac Kenzie, W.R., Hoxie, N.J., Proctor, M.E., Gradus, M.S., Blair, K.A., Peterson, D.E., et al. (1994) A massive outbreak in Milwaukee of Cryptosporidium infection transmitted through the public water supply. New England Journal of Medicine, 331, 161-167. doi:10.1056/NEJM199407213310304

[6] Fayer, R., Morgan, U. and Upton, S.J. (2000) Epidemiology of Cryptosporidium: Transmission, detection and identification. International Journal for Parasitology, 30, 1305-1322. doi:10.1016/S0020-7519(00)00135-1

[7] Sunnotel, O., Lowery, C.J., Moore, J.E., Dooley, J.S., Xiao, L., Millar, B.C., et al. (2006) Cryptosporidium. Letters in Applied Microbiology, 43, 7-16. doi:10.1111/j.1472-765X.2006.01936.X

[8] Xiao, L. and Ryan, U.M. (2008) Molecular epidemiology. In: Fayer, R. and Xiao, L., Eds., Cryptosporidium and Cryptosporidiosis, CRC Press and IWA Publishing, Boca Raton, 119-171.

[9] Craun, G.F., Calderon, R.L. and Craun, M.F. (2005) Out- 
breaks associated with recreational water in the United States. International Journal of Environmental Health Research, 15, 243-262. doi:10.1080/09603120500155716

[10] Yoder, J.S., Harral, C., Beach, M.J. and Centers for Disease Control and Prevention (CDC) (2010) Cryptosporidiosis surveillance-United States, 2006-2008. Morbidity and Mortality Weekly Report Surveillance Summaries, 59, 1-14.

http://www.cdc.gov/mmwr/preview/mmwrhtml/ss5906a1.htm

[11] Yoder, J.S., Wallace, R.M., Collier, S.A., Beach, M.J., Hlavsa, M.C. and Centers for Disease Control and Prevention (CDC) (2012) Cryptosporidiosis surveillance-United States, 2009-2010. Morbidity and Mortality Weekly Report Surveillance Summaries, 61, 1-12. http://www.cdc.gov/mmwr/preview/mmwrhtml/ss6105a1.htm

[12] Benson, C.A., Kaplan, J.E., Masur, H., Pau, A. and Holmes, K.K. (2004) Treating opportunistic infections among HIV-infected adults and adolescents: Recommendations from CDC, the National Institutes of Health, and the HIV Medicine Association/Infectious Diseases Society of America. Morbidity and Mortality Weekly Report Recommendations and Reports, 53, 1-112.

http://www.cdc.gov/mmwr/preview/mmwrhtml/rr5315a1. $\underline{\mathrm{htm}}$

[13] Fox, L.M. and Saravolatz, L.D. (2005) Nitazoxanide: A new thiazolide antiparasitic agent. Clinical Infectious $\mathrm{Di}$ seases, 40, 1173-1180. doi:10.1086/428839

[14] Casemore, D.P. (1991) Laboratory methods for diagnosing cryptosporidiosis. Journal of Clinical Pathology, 44, 445-451. doi:10.1136/jcp.44.6.445

[15] Morgan, U.M., Pallant, L., Dwyer, B.W., Forbes, D.A., Rich, G. and Thompson, R.C. (1998) Comparison of PCR and microscopy for detection of Cryptosporidium parvum in human fecal specimens: Clinical trial. Journal of Clinical Microbiology, 36, 995-998.

http://jcm.asm.org/content/36/4/995.long

[16] Glaberman, S., Moore, J.E., Lowery, C.J., Chalmers, R.M., Sulaiman, I., Elwin, K., et al. (2002) Three drinking-water-associated cryptosporidiosis outbreaks, Northern Ireland. Emerging Infectious Diseases, 8, 631-633. doi:10.3201/eid0806.010368

[17] Alves, M., Xiao, L., Sulaiman, I., Lal, A.A., Matos, O. and Antunes, F. (2003) Subgenotype analysis of Cryptosporidium isolates from humans, cattle, and zoo ruminants in Portugal. Journal of Clinical Microbiology, 41, 2744-2747. doi:10.1128/JCM.41.6.2744-2747.2003

[18] Chan, R., Chen, J., York, M.K., Setijono, N., Kaplan, R.L., Graham, F., et al. (2000) Evaluation of a combination rapid immunoassay for detection of Giardia and Cryptosporidium antigens. Journal of Clinical Microbiology, 38, 393-394. http://jcm.asm.org/content/38/1/393.long

[19] Sharp, S.E., Suarez, C.A., Duran, Y. and Poppiti, R.J. (2001) Evaluation of the triage micro parasite panel for detection of Giardia lamblia, Entamoeba histolytica/Entamoeba dispar, and Cryptosporidium parvum in patient stool specimens. Journal of Clinical Microbiology, 39, 332-334. doi:10.1128/JCM.39.1.332-334.2001

[20] Alles, A.J., Waldron, M.A., Sierra, L.S. and Mattia, A.R.
(1995) Prospective comparison of direct immunofluorescence and conventional staining methods for detection of Giardia and Cryptosporidium spp. in human fecal specimens. Journal of Clinical Microbiology, 33, 1632-1634. http://jcm.asm.org/content/33/6/1632.long

[21] Arrowood, M.J., Hurd, M.R. and Mead, J.R. (1995) A new method for evaluating experimental cryptosporidial parasite loads using immunofluorescent flow cytometry. The Journal of Parasitology, 81, 404-409. http://dx.doi.org/10.2307/3283822

[22] Valdez, L.M., Dang, H., Okhuysen, P.C. and Chappell, C.L. (1997) Flow cytometric detection of Cryptosporidium oocysts in human stool samples. Journal of Clinical Microbiology, 35, 2013-2017. http://jcm.asm.org/content/35/8/2013.long

[23] Vesey, G., Deere, D., Weir, C.J., Ashbolt, N., Williams, K.L. and Veal, D.A. (1997) A simple method for evaluating Cryptosporidium-specific antibodies used in monitoring environmental water samples. Letters in Applied Microbiology, 25, 316-320.

doi:10.1046/j.1472-765X.1997.00237.x

[24] Barbosa, J.M., Costa-de-Oliveira, S., Rodrigues, A.G., Hanscheid, T., Shapiro, H. and Pina-Vaz, C. (2008) A flow cytometric protocol for detection of Cryptosporidium spp. Cytometry A, 73, 44-47. doi:10.1002/cyto.a.20502

[25] Codices, V., Martins, C., Novo, C., Pinho, M., de Sousa, B., Lopes, A., et al. (2013) Cell phenotypic change due to Cryptosporidium parvum infection in immunocompetent mice. Acta Parasitologica, 58, 70-79. doi:10.2478/s11686-013-0113-2

[26] Codices, V., Martins, C., Novo, C., de Sousa, B., Lopes, A., Borrego, M., et al. (2013) Dynamics of cytokines and immunoglobulins serum profiles in primary and seconddary Cryptosporidium parvum infection: Usefulness of Luminex ${ }^{\mathbb{B}}$ xMAP technology. Experimental Parasitology, 133, 106-113. doi:10.1016/i.exppara.2012.11.003

[27] Snelling, W.J., Lin, Q., Moore, J.E., Millar, B.C., Tosini, F., Pozio, E., et al. (2007) Proteomics analysis and protein expression during sporozoite excystation of Cryptosporidium parvum (Coccidia, Apicomplexa). Molecular \& Cellular Proteomics, 6, 346-355. doi:10.1074/mcp.M600372-MCP200

[28] Bradford, M.M. (1976) A rapid and sensitive method for the quantitation of microgram quantities of protein utilizing the principle of protein-dye binding. Analytical Biochemistry, 72, 248-254. doi:10.1016/0003-2697(76)90527-3

[29] Clark, M.F. and Adams, A.N. (1977) Characteristics of the microplate method of enzyme-linked immunosorbent assay for the detection of plant viruses. The Journal of General Virology, 34, 475-483. doi:10.1099/0022-1317-34-3-475

[30] King, T. (1989) A modified method for glutaraldehyde fixation of cells to a solid phase surface. Journal of Tissue Culture Methods, 12, 107-109. doi:10.1007/BF01404495

[31] Köhler, G. and Milstein, C. (1975) Continuous cultures of fused cells secreting antibody of predefined specificity. 
Nature, 256, 495-497. doi:10.1038/256495a0

[32] Garcia, L.S., Brewer, T.C. and Bruckner, D.A. (1987) Fluorescence detection of Cryptosporidium oocysts in human fecal specimens by using monoclonal antibodies. Journal of Clinical Microbiology, 25, 119-121. http://jcm.asm.org/content/25/1/119.long

[33] Arrowood, M.J. and Sterling, C.R. (1989) Comparison of conventional staining methods and monoclonal antibodybased methods for Cryptosporidium oocyst detection. Journal of Clinical Microbiology, 27, 1490-1495. http://jcm.asm.org/content/27/7/1490.long

[34] Alves, M., Matos, O. and Antunes, F. (2001) Multilocus PCR-RFLP analysis of Cryptosporidium isolates from HIV-infected patients from Portugal. Annals of Tropical Medicine and Parasitology, 95, 627-632.

[35] Cacciò, S.M., De Giacomo, M. and Pozio, E. (2002) Sequence analysis of the $\beta$-giardin gene and development of a polymerase chain reaction-restriction fragment length polymorphism assay to genotype Giardia duodenalis cysts from human faecal samples. International Journal for Parasitology, 32, 1023-1030. doi:10.1016/S0020-7519(02)00068-1

[36] Clarke, S.C. and McIntyre, M. (2001) Acid-fast bodies in faecal smears stained by the modified Ziehl-Neelsen technique. British Journal of Biomedical Science, 58, 7-10.

[37] Rusnak, J., Hadfield, T.L., Rhodes, M.M. and Gaines, J.K. (1989) Detection of Cryptosporidium oocysts in human fecal specimens by an indirect immunofluorescence assay with monoclonal antibodies. Journal of Clinical Microbiology, 27, 1135-1136. http://jcm.asm.org/content/27/5/1135.long

[38] Magi, B., Canocchi, V., Tordini, G., Cellesi, C. and Barberi, A. (2006) Cryptosporidium infection: Diagnostic techniques. Parasitology Research, 98, 150-152. doi:10.1007/s00436-005-0050-6

[39] Smith, H. (2008) Diagnostics. In: Fayer, R. and Xiao, L. Eds., Cryptosporidium and Cryptosporidiosis, CRC Press and IWA Publishing, Boca Raton, 173-207.

[40] Rodgers, M.R., Flanigan, D.J. and Jakubowski, W. (1995) Identification of algae which interfere with the detection of Giardia cysts and Cryptosporidium oocysts and a method for alleviating this interference. Applied and Environmental Microbiology, 61, 3759-3763. http://aem.asm.org/content/61/10/3759.long

[41] Bull, S., Chalmers, R., Sturdee, A.P., Curry, A. and Kennaugh, J. (1998) Cross-reaction of an anti-Cryptosporidium monoclonal antibody with sporocysts of Monocystis species. Veterinary Parasitology, 77, 195-197. doi:10.1016/S0304-4017(97)00090-3

[42] Kehl, K.S., Cicirello, H. and Havens, P.L. (1995) Comparison of four different methods for detection of Cryptosporidium species. Journal of Clinical Microbiology, 33, 416-418. http://jcm.asm.org/content/33/2/416.long

[43] Garcia, L.S. and Shimizu, R.Y. (1997) Evaluation of nine immunoassay kits (enzyme immunoassay and direct fluorescence) for detection of Giardia lamblia and Cryptosporidium parvum in human fecal specimens. Journal of Clinical Microbiology, 35, 1526-1529. http://jcm.asm.org/content/35/6/1526.long

[44] Cole, D.J., Snowden, K., Cohen, N.D. and Smith, R. (1999) Detection of Cryptosporidium parvum in horses: Thresholds of acid-fast stain, immunofluorescence assay, and flow cytometry. Journal of Clinical Microbiology, 37, 457-460. http://jcm.asm.org/content/37/2/457.long

[45] Hsu, B.M., Wu, N.M., Jang, H.D., Shih, F.C., Wan, M.T. and Kung, C.M. (2005) Using the flow cytometry to quantify the Giardia cysts and Cryptosporidium oocysts in water samples. Environmental Monitoring and Assessment, 104, 155-162. doi:10.1007/s10661-005-1608-6 